\title{
Effects of age on estimated familiarity in the process dissociation procedure: The role of noncriterial recollection
}

\author{
JEFFREY P. TOTH \\ University of North Carolina, Wilmington, North Carolina \\ and \\ COLLEEN M. PARKS \\ University of California, Davis, California
}

\begin{abstract}
Research on recognition memory using the process dissociation procedure has suggested that although recollection $(R)$ declines with age, familiarity $(F)$ remains age invariant. However, this research has used relatively broad definitions of $R$. An important question concerns age-related changes in memory when $R$ is defined in terms of specific event details. Yonelinas and Jacoby (1996a) required young participants to recollect specific, criterial details of a prior event and found evidence that recollection of noncriterial details elevated estimates of $F$ yet still operated automatically. In the present study, the issue of noncriterial recollection was examined in the context of aging. The results replicated the effects of noncriterial recollection for the young, but not for the older adults, who also showed overall reduced levels of familiarity.
\end{abstract}

Dual-process theories of memory propose that recognition decisions can be made on the basis of either recollection or familiarity (Atkinson \& Juola, 1974; Jacoby, 1991; Mandler, 1980). Recollection is thought to involve conscious retrieval of the episodic details of a prior event, whereas familiarity is thought to reflect undifferentiated feelings of oldness that occur in the absence of memory for specific episodic details. Evidence supporting this distinction has come from a variety of sources, including behavioral experiments with healthy adults (e.g., Hintzman, Caulton, \& Levitin, 1998; Jacoby, 1999; Toth, 1996; Yonelinas, 1997, 2001), behavioral experiments with memory-disordered populations (e.g., Aggleton \& Shaw, 1996; Verfaellie \& Treadwell, 1993; Yonelinas, Kroll, Dobbins, Lazzara, \& Knight, 1998), and experiments in which neural activity has been investigated during the performance of recognition memory tasks (e.g., Curran, 2000; Henson, Rugg, Shallice, Josephs, \& Dolan, 1999; Yonelinas, Hopfinger, Buonocore, Kroll, \& Baynes, 2001). Yonelinas (2002) provides an excellent review of each of these areas.

This research was presented in April 2000 at the 8th Cognitive Aging Conference in Atlanta and was supported by a traineeship awarded to C.M.P. by the National Institute of Aging (T32 AG0175). The authors thank Karen Daniels for her support in conducting the research and for her insightful comments on relevant theoretical issues. Correspondence concerning this research can be directed to J. P. Toth, Department of Psychology, 601 South College Road, University of North Carolina, Wilmington, NC 28403 (e-mail: tothj@uncw.edu).

Note-This article was accepted by the previous editorial team, when Colin M. MacLeod was Editor.
One influential technique for separating and measuring recollection and familiarity is the process dissociation (PD) procedure. As originally described by Jacoby (1991), participants first study two sets of items, each presented within a distinctive context (e.g., List 1 and List 2). Memory for these items is then assessed in separate inclusion and exclusion test conditions, each of which contains items from List 1, items from List 2, and new (unstudied) items. In the inclusion condition, participants are asked to accept (say "yes" to) items originally studied in either List 1 or List 2 and to reject (say "no" to) new items. In the exclusion condition, in contrast, participants are asked to accept only items from List 2 and to reject both new items and those from List 1 . Note that in this description, List 1 represents the list of interest, since it is only items from this list that the participants are instructed to both accept and reject (in the inclusion and exclusion tests, respectively).

Estimates of recollection and familiarity for items from the target study context (List 1) are computed from equations representing performance in the two test conditions. Thus, assuming independence between recollection and familiarity, the probability of accepting List 1 items in the inclusion condition can be expressed as the probability that those items are recollected $(R)$ plus the probability that those items are familiar $(F)$ in the absence of recollection [i.e., $p$ ("yes" $\mid$ inclusion $)=R+F(1-R)$ ]. Acceptance of List 1 items in the exclusion condition, in contrast, reflects the probability that those items are familiar in the absence of recollection [i.e., $p$ ("yes"| exclusion) $=$ $F(1-R)]$. Given overall performance in the inclusion and exclusion conditions [i.e., $p$ ("yes"| List 1 items)], a mea- 
sure of $R$ can be obtained by subtracting performance in the exclusion condition from that in the inclusion condition $[R=$ inclusion - exclusion]. And given an estimate of $R$, an estimate of $F$ can be obtained with simple algebra [e.g., $F=$ exclusion/ $(1-R)]$.

The PD procedure has been quite successful in producing theoretically meaningful estimates of recollection and familiarity as a function of variables thought to be relevant to memory performance. For example, variables that are generally agreed to impair cognitive control-such as divided attention at study and speeded responding at testhave been shown to produce reliable decrements in estimates of recollection but to have no influence on estimates of familiarity (e.g., Jacoby \& Kelley, 1992; SchmitterEdgecombe, 1999; Toth, 1996). Aging has also been found to dissociate the two processes, with older adults consistently showing lower estimates of recollection than do younger adults, whereas estimates of familiarity have often been found to be equivalent in the two groups (Caldwell \& Masson, 2001; Jacoby, 1996, 1999; Jennings \& Jacoby, 1993, 1997; Rybash \& Hoyer, 1996; Titov \& Knight, 1997; but see Light, Prull, La Voie, \& Healy, 2000). This pattern of results is consistent with theories suggesting that aging is associated with deficits in cognitive control, whereas more automatic processes remain relatively intact (e.g., Braver \& Barch, 2002; Craik \& Grady, 2002; Jacoby, Jennings, \& Hay, 1996; Park, Polk, Mikels, Taylor, \& Marshuetz, 2001; Stuss, Craik, Sayer, Franchi, \& Alexander, 1996).

Despite the above successes, the PD procedure has generated a good deal of controversy (e.g., Curran \& Hintzman, 1995, 1997; Graf \& Komatsu, 1994; Humphreys, Dennis, Chalmers, \& Finnigan, 2000; Jacoby, 1998; Jacoby, Begg, \& Toth, 1997; Toth, Reingold, \& Jacoby, 1995). In the present article, we focus on one of the more conceptual controversies associated with the procedure, one with important implications for both dual-process theories of memory and our understanding of how memory changes with age. In particular, we examine the claim that PD estimates of familiarity are influenced not only by undifferentiated feelings of familiarity, but also by the recollection of episodic details that are irrelevant for correct responding in inclusion and exclusion conditions (Dodson \& Johnson, 1996; Gruppuso, Lindsay, \& Kelley, 1997; Mulligan \& Hirshman, 1997). This phenomenon originally was described by Gruppuso, Lindsay, and Kelley (1995) and later was termed noncriterial recollection by Yonelinas and Jacoby (1996a).

\section{The Effect of Noncriterial Recollection on Estimates of Familiarity}

To understand the phenomenon of noncriterial recollection, consider an experiment by Yonelinas and Jacoby (1996a). At study, participants saw a list of words that varied orthogonally in terms of their screen location (left/ right) and font size (small/large), with instructions to remember each word's location. Next, the participants took a PD (inclusion/exclusion) recognition test in which test words were presented in the center of the computer screen in a medium-sized font. Half of the participants were tested on each word's location at study, and half were tested on the word's earlier size. Consistent with the instructions to remember location, Yonelinas and Jacoby (1996a) found that estimated recollection was higher in the location test than in the size test. Estimates of familiarity, however, showed the opposite pattern, being significantly greater in the size condition than in the location condition. Given that the participants in the two test conditions (location vs. size) had the same study experience, there is no obvious reason why words in the size test should be more familiar than those in the location test.

What, then, accounts for the elevated estimates of familiarity in the size condition? Yonelinas and Jacoby (1996a) suggested that the elevation reflected noncriterial recollection of the words' prior locations. That is, although attempts to remember a word's prior size often failed, such attempts nevertheless often resulted in recollection of the word's earlier location. But because location was noncriterial with respect to the goals of the size test (i.e., it could not support discriminative responding), memory for this attribute could not contribute to the estimate of recollection. Recollection of location did, however, clearly indicate that the word was previously studied; and given the standard PD instruction to accept all previously studied words, this recollection of noncriterial location information ended up being measured as familiarity.

Although this explanation seems reasonable, the results themselves would seem to be highly problematic for the PD procedure. Theoretically, those results appear to show that recollection may often be incorrectly measured as familiarity in the PD procedure. Moreover, by showing a negative relation between $R$ and $F$, the results would appear to violate the independence assumption underlying use of the procedure. Before accepting these conclusions, however, Yonelinas and Jacoby (1996a) considered another possibility - that noncriterial recollection may be functionally the same as familiarity. They noted that introspectively, noncriterial recollection often occurs quickly and with little or no conscious effort, characteristics often ascribed to familiarity (see also Dodson, Holland, \& Shimamura, 1998). More generally, they argued that if noncriterial recollection can be shown to function independently of criterial recollection, it would pose no problem for the assumptions underlying the PD procedure.

To examine these possibilities, Yonelinas and Jacoby (1996a) also manipulated response speed in the experiment described above. That is, whereas half of the participants were allowed to make test responses at their own pace, the other half were given a response deadline of $1.2 \mathrm{sec}$. Previous research has shown that limiting retrieval time may often have a large, detrimental effect on recollection but leave familiarity unchanged (Toth, 1996; Yonelinas \& Jacoby, 1994). Thus, if noncriterial recollection is similar to criterial recollection, familiarity estimates in the more difficult size condition should be reduced in the speeded condition, and the problems noted above would be confirmed. Alternatively, if noncriterial recollection is more akin to familiarity, estimates of familiarity should remain 
invariant across the deadline manipulation, suggesting functional independence between criterial and noncriterial recollection and no fundamental problem with the PD procedure.

In fact, the results clearly supported the latter possibility. Although estimates of recollection were greatly reduced by the deadline manipulation (by approximately $20 \%$ ), this manipulation had no reliable influence on estimates of familiarity, despite the fact that those estimates were affected by noncriterial recollection. The invariance in familiarity as a function of response deadline suggests that noncriterial recollection can operate in the same manner as familiarity - automatically and independently of criterial recollection.

\section{Noncriterial Recollection and Aging}

This finding that noncriterial recollection can operate in the same manner as familiarity raises an interesting and theoretically important question with respect to aging. Noncriterial recollection was so named because it presumably reflects memory for episodic details. As such, one might predict the influence of noncriterial recollection to be reduced in older adults, in comparison with younger adults, given clear evidence of age-related declines in episodic memory (e.g., Balota, Dolan, \& Duchek, 2000; Craik \& Jennings, 1992). In contrast, the idea that noncriterial recollection operates automatically, as Yonelinas and Jacoby (1996a) have claimed, predicts equivalent levels of noncriterial recollection in young and older adults, given that automatic processes are typically unaffected by aging (e.g., La Voie \& Light, 1994). Deciding between these alternative predictions is important because if we were to find no age differences with respect to noncriterial recollection (which appears possible, given Yonelinas \& Jacoby's, 1996a, results), it would indicate a form of automatic memory for contextual, episodic details that is preserved in older adults.

To test these alternative predictions, we employed Yonelinas and Jacoby's (1996a) experimental paradigm but examined the effects of age, instead of response deadline, and used location and color as the easy and difficult dimensions, respectively. We expected that young adults would show greater recollection than would older adults and that both age groups would show greater recollection of the easy detail (location) than of the more difficult detail (color). The main question of interest concerned estimated familiarity. If noncriterial recollection operates automatically and is functionally independent of criterial recollection, its effects on estimated familiarity should be similar in young and older adults. Alternatively, if noncriterial recollection is tied to criterial recollection, its effects on estimated familiarity should be reduced in older adults.

\section{METHOD}

\section{Participants}

Seventy-two young adults and 78 older adults were initially tested. The young adults were Georgia Tech students who participated for course credit, and the older adults were from the Atlanta community and participated for a payment of $\$ 10$. Six older participants were excluded from the final data analysis, 1 for failing to follow instructions and 5 for having false alarm rates that exceeded $50 \%$. Thus, the final set included 72 young adults (mean age $=19.8$ years, $S D=1.8 ; 37$ female) with a mean self-reported education of 13.7 years $(S D=1.3)$ and 72 older adults (mean age $=71.1$ years, $S D=$ $4.4 ; 45$ female) with a mean self-reported education of 15.3 years $(S D=2.4)$. Performance on the Shipley vocabulary test was reliably greater in the older participants $(35.76, S D=4.05)$ than in the younger participants $(31.65, S D=3.29)[t(116)=5.77, p<.01]{ }^{1}$ Participants from both age groups were randomly assigned to the retrieval condition (location vs. color), for a total of 36 young and 36 older adults per condition.

\section{Design}

The experiment used a $2 \times 2 \times 2$ mixed design, with age (young or old) and retrieval attribute (location or color) as betweenparticipants factors and type of test trial (inclusion or exclusion) as the within-participants factor. This design was very similar to that used by Yonelinas and Jacoby (1996a), except that age was examined, instead of response speed, and location and color acted as the two target dimensions, instead of location and size, because pilot testing had shown near-zero levels of recollection for size. Note also that, as will be described more fully below (see the Procedure section), we used the two-question variant of the inclusion/exclusion PD procedure introduced by Yonelinas (1994). Unlike Jacoby's (1991) original procedure (described in the introduction), the twoquestion variant requires the same degree of source discrimination in the inclusion and exclusion conditions, thus avoiding a potential confound between test condition and memory demands.

In overview, all the participants first studied a list of words that appeared randomly on the left and right of the computer screen and randomly in the colors red and green. They then received a recognition test containing both studied and unstudied words, presented in the center of the screen in white. Inclusion and exclusion conditions occurred randomly throughout the test, implemented by a question that accompanied each test word. For half of the participants, the questions asked about each word's prior location (location condition); for the other half, the questions asked about each word's prior color (color condition).

\section{Materials and Counterbalancing}

Critical items consisted of 144 five-letter words, separated into six sets (A-F) of 24 that were equated for mean frequency (from 44.00 to 44.04 occurrences per million; Kučera \& Francis, 1967) and roughly equated for the number of words having the same first letter. For each participant, four sets served as studied words, and two sets served as unstudied words at test. Thus, the study list consisted of 96 critical words, and the test lists consisted of 144 words. Lists were rotated through conditions, so that all the words served equally often as studied and unstudied items. In addition to the critical study words, 8 buffer words ( 4 primacy and 4 recency) were presented at study and also served as practice test items.

For participants assigned to the location condition, the study lists consisted of two sets of items (e.g., A and B) that appeared on the left of the screen and two sets (e.g., C and D) that appeared on the right, with both the order of words in the lists and the presentation order of locations randomly determined. The color of the words (the noncriterial dimension for this group) was randomly assigned, irrespective of list, with the constraint that half of the words appeared in red and half in green. Word sets were rotated across participants in this group, so that all the words occurred equally often on the left and the right. This same scheme was used for the participants in the color condition. That is, two list sets were assigned to each color; the order of words in the lists and the presentation order of colors was random. Word location (noncriterial for this group) was randomly assigned, irrespective of list, with the constraint that half 
of the words appeared on the left and half on the right. The lists were rotated across participants, so that all the words occurred equally often in red and in green.

The final counterbalance involved assignment of words to the inclusion and exclusion test conditions. Thus, within each of the list rotations described above, two test versions were created, so that word sets presented as inclusion items in the first version were presented as exclusion items in the second, and vice versa. This rotation of item sets also occurred for the unstudied test items (e.g., sets E and F).

\section{Procedure}

The participants were tested individually with the experimenter present. Instructions were given in written form on the computer screen and then were reiterated by the experimenter. Study and test words were presented on a 17 -in. monitor with a black background, using Turbo Pascal's (Version 5.0) sans serif font at default size 4; thus, each letter was approximately $7 \times 7 \mathrm{~mm}$.

The participants first were told that they were taking part in a memory experiment and then were given instructions for the study phase. For this phase, words were presented one at a time on the left or right side of the screen (approximately $12 \mathrm{~cm}$ from the midpoint), with each word occurring in either red or green. Words were presented for $3 \mathrm{sec}$, separated by a 1 -sec blank screen, and the participants were required to say each word aloud. In addition to remembering the words, the participants were also told to remember each word's location and color, although location was described as the "most important" feature to remember. To encourage memory for location, the instructions described an optional mnemonicassociating each side of the screen with a different person or place. The study list lasted approximately $6 \mathrm{~min}$.

Immediately following study, the participants were given instructions for the memory test. The participants in the location (easy) condition were told that their memory would be tested for the studied words, as well as for their prior locations. Each trial consisted of a test word presented in the center of the screen in white, with a question presented above it (in light cyan). The question was either "Was this word on the LEFT?" or "Was this word on the RIGHT?" Inclusion and exclusion conditions were created by crossing the actual location of the word at study with the location queried at test (see Table 1). That is, the inclusion condition was created by asking congruent questions (e.g., asking "Was this word on the LEFT?" for a test word that had been presented on the left at study), whereas the exclusion condition was created by asking incongruent questions (i.e., asking "Was this word on the LEFT?" for a test word that had been presented on the right at study). The participants were told that if they could recollect a test word's study location, they were simply to answer the question (saying "yes" or "no"). If they could not remember the word's prior location but remembered the word as having been presented on the study list, they were to respond "yes." Finally, they were to respond "no" if they did not remember the word being presented at study. Instructions and displays for the color (difficult) condition were identical, except that the questions asked about each word's prior color ("Was this word in RED?" or "Was this word in GREEN?").

Note how the inclusion and exclusion conditions are created by these questions. In the color condition, for example, if recollection of a word's prior color was perfect $(R=1.0)$, performance [ $p$ ("yes")] would be 1.0 in the inclusion condition and 0.0 in the exclusion condition. Alternatively, if an individual had no recollection of color $(R=0.0)$, performance in the inclusion and exclusion conditions would be identical, with the overall level determined by the strength of familiarity (and/or the recollection of noncriterial details).

The participants in both groups were discouraged from guessing about a word's prior attributes. The order of test conditions (words and questions) was random. Six practice trials (four study buffers and two unstudied items) were given in order to familiarize the participants with the test procedure and to evaluate their understanding of the instructions. The memory test began immediately after practice, and the experimenter entered all responses. The entire experimental session lasted about $45 \mathrm{~min}$. The significance level for statistical comparisons was set at .05 .

\section{RESULTS AND DISCUSSION}

Two sets of analyses were conducted. We first compared performance in the two retrieval conditions (location vs. color), separately for the young and older adults, in order to assess evidence for noncriterial recollection. In a second set of analyses, we then directly compared young and older adults in order to assess differences in noncriterial recollection and in overall levels of estimated familiarity. To anticipate, we replicated the effect of noncriterial recollection on estimated familiarity for young adults (Gruppuso et al., 1997; Mulligan \& Hirshman, 1997; Yonelinas \& Jacoby, 1996a) but failed to find evidence for this effect in the older adults. We also found overall lower familiarity estimates for older adults than for the young.

\section{Memory for Location Versus Color in Young Adults}

Mean proportions of "yes" responses on inclusion, exclusion, and baseline trials for the young adults are presented in the top two rows of Table 2. A mixed-model ANOVA with retrieval attribute (location or color) as the between-participants factor and trial type (inclusion or exclusion) as the within-participants factor revealed main effects of both retrieval attribute $\left[F(1,70)=14.37, M S_{\mathrm{e}}=\right.$ $0.02501, p<.001]$ and trial type $\left[F(1,70)=87.31, M S_{\mathrm{e}}=\right.$ $0.01428, p<.001]$, as well as a significant interaction between the two $\left[F(1,70)=47.41, M S_{\mathrm{e}}=0.01428, p<\right.$

Table 1

Assignment of Trials to Inclusion and Exclusion Conditions

\begin{tabular}{cccc}
\hline \multirow{2}{*}{ Condition } & Actual Study Location & "Left?" & "Right?" \\
\cline { 3 - 4 } Location (easy) & Left & inclusion & exclusion \\
& Right & exclusion & inclusion \\
& & \multicolumn{2}{c}{ Test Question } \\
\cline { 3 - 4 } Color (difficult) & Actual Study Color & "Red?" & "Green?" \\
\cline { 2 - 4 } & Red & inclusion & exclusion \\
& Green & exclusion & inclusion \\
\hline
\end{tabular}


Table 2

Mean Proportions (With Standard Deviations) of "Yes" Responses as a Function of Age, Test Condition, and Type of Test Trial

\begin{tabular}{|c|c|c|c|c|c|c|}
\hline \multirow[b]{3}{*}{ Condition } & \multicolumn{6}{|c|}{ Test Trial } \\
\hline & \multicolumn{2}{|c|}{ Inclusion } & \multicolumn{2}{|c|}{ Exclusion } & \multicolumn{2}{|c|}{ Baseline } \\
\hline & $M$ & $S D$ & $M$ & $S D$ & $M$ & $S D$ \\
\hline \multicolumn{7}{|l|}{ Young adults } \\
\hline Location (easy) & .69 & .14 & .36 & .16 & .14 & .11 \\
\hline Color (difficult) & .65 & .12 & .60 & .14 & .11 & .08 \\
\hline \multicolumn{7}{|l|}{ Older adults } \\
\hline Location (easy) & .60 & .14 & .45 & .16 & .21 & .12 \\
\hline Color (difficult) & .59 & .17 & .58 & .18 & .23 & .10 \\
\hline
\end{tabular}

.001]. The interaction reflected the larger difference between inclusion and exclusion performance in the location condition than in the color condition, suggesting greater recollection for prior locations. Baseline performance [ $p$ ("yes" $\mid$ unstudied item)] was not significantly different between the location and the color conditions $[F(1,70)=$ $1.49, p=.23]$.

Mean estimates of recollection and familiarity computed for each participant, using the equations described earlier, are shown in the top two rows of Table 3. Note that estimated $F$ is presented in three ways; as the unadjusted mean, as "corrected $F$ " (i.e., $F$ minus baseline), and as $d^{\prime}$ (see Yonelinas \& Jacoby, 1996b). ${ }^{2}$ A one-way ANOVA showed $R$ to be greater in the location condition than in the color condition $\left[F(1,70)=47.71, M S_{\mathrm{e}}=0.02855, p<\right.$ $.001]$. Estimated $F$, however, showed the opposite pattern, being greater in the color condition than in the location condition, regardless of which index of $F$ was employed [lowest $F(1,70)=8.05, p<.01]$. It is worth noting that the .10 difference that we obtained in estimated $F$ between the two retrieval conditions (i.e., the size of the noncriterial recollection effect) was very close to the difference of .11 obtained by Yonelinas and Jacoby (1996a) in their participant-paced test condition. Overall, then, the present experiment successfully replicated previous research showing an inverse relation between estimates of recollection and familiarity across retrieval conditions differing in difficulty (Yonelinas \& Jacoby, 1996a) or similarity (Gruppuso et al., 1997; Mulligan \& Hirshman, 1997).
Moreover, the overall pattern of estimates - especially the greater $R$ in the location condition - is consistent with the idea that noncriterial recollection for location acted to elevate estimates of $F$ in the more difficult color condition.

\section{Memory for Location Versus Color in Older Adults}

Mean proportions of "yes" responses given by older adults are presented in the bottom two rows of Table 2. A mixed-model ANOVA on the study items revealed a main effect of trial type $\left[F(1,70)=29.63, M S_{\mathrm{e}}=0.00832, p<\right.$ $.001]$. The main effect of retrieval attribute did not reach significance $\left[F(1,70)=2.77, M S_{\mathrm{e}}=0.04319, p=.10\right]$, but the interaction between retrieval attribute and trial type was reliable $\left[F(1,70)=21.27, M S_{\mathrm{e}}=0.00832, p<.001\right]$. As for the young adults, the interaction reflected the larger difference between inclusion and exclusion performance in the location condition than in the color condition, suggesting greater recollection of locations. Indeed, for the older adults, inclusion and exclusion scores in the color condition were nearly identical, suggesting little or no recollection for prior colors. Baseline performance was not significantly different between the location and the color conditions $(F<1)$.

Mean estimates of recollection and familiarity are shown in the bottom two rows of Table 3. One-way ANOVAs showed that $R$ was greater in the location condition than in the color condition $[F(1,70)=21.27, p<.001]$. In contrast to the results for the young adults, however, estimated $F$ was not reliably different across the two conditions, regardless of which index was employed [with $F(1,70)$ values of $2.09,1.02$, and 0.43 for the unadjusted estimate, corrected $F$, and $d^{\prime}$ scores, respectively; lowest $p>.15$ ]. Given that these are null effects and that all measures of familiarity showed a trend favoring the color condition, we conducted power analyses using the young adults condition differences (color minus location) as the relevant effect sizes (leading to $d$ values of $.77, .86$, and .68 for the unadjusted $F$, corrected $F$, and $d^{\prime}$ measures, respectively); at an alpha level of .05 , the power to detect differences of these magnitudes in the present study was .88 and greater. It would therefore appear that at least under the conditions studied here, older adults do not show the inverse relation

Table 3

Means (With Standard Deviations) for Estimated Recollection and Familiarity as a Function of Age and Test Condition

\begin{tabular}{|c|c|c|c|c|c|c|c|c|}
\hline \multirow[b]{3}{*}{ Condition } & \multicolumn{8}{|c|}{ Memory Estimate } \\
\hline & \multicolumn{2}{|c|}{ Recollection } & \multicolumn{2}{|c|}{ Familiarity } & \multicolumn{2}{|c|}{ Corrected $F$} & \multicolumn{2}{|c|}{$d^{\prime}$} \\
\hline & $M$ & $S D$ & $M$ & $S D$ & $M$ & $S D$ & $M$ & $S D$ \\
\hline \multicolumn{9}{|l|}{ Young adults } \\
\hline Location (easy) & .32 & .22 & .53 & .13 & .40 & .14 & 1.33 & 0.53 \\
\hline Color (difficult) & .05 & .10 & .63 & .13 & .52 & .14 & 1.73 & 0.61 \\
\hline \multicolumn{9}{|l|}{ Older adults } \\
\hline Location (easy) & .15 & .16 & .53 & .16 & .32 & .14 & 0.96 & 0.44 \\
\hline Color (difficult) & .01 & .10 & .59 & .17 & .35 & .18 & 1.04 & 0.55 \\
\hline
\end{tabular}

Note-Corrected $F=$ estimated familiarity minus baseline (computed separately for each participant). $d^{\prime}=$ familiarity-based discriminability (see the text for details). 
between estimates of recollection and familiarity found for the young adults and in prior research.

\section{Recollection and Familiarity in Young Versus Older Adults}

Analysis of baseline scores revealed a main effect of age $\left[F(1,140)=33.84, M S_{\mathrm{e}}=0.01092, p<.001\right]$, with older adults saying "yes" to unstudied words significantly more often than the young (for similar results, see Benjamin \& Craik, 2001; Searcy, Bartlett, \& Memon, 1999). The main effect of retrieval attribute on baseline performance was not reliable $(F<1)$, nor was the interaction between age and retrieval condition $(F=1.58, p>.20)$. The lack of baseline differences between the two retrieval attribute conditions allows estimated $R$ to be directly compared for the two age groups. However, the age difference in baseline performance complicates the comparison of estimated $F$ across the age groups, because differences in baseline affect the overall magnitude of unadjusted $F$ estimates (see Yonelinas \& Jacoby, 1996b). We therefore focused on the two adjusted measures, corrected $F$ and $d^{\prime}$, in order to assess age differences in the effects of noncriterial recollection and in overall levels of familiarity.

A univariate analysis of estimated recollection $(d f=1$, $\left.140 ; M S_{\mathrm{e}}=0.02260\right)$ revealed main effects of both age $(F=17.01, p<.001)$ and retrieval condition $(F=68.71$, $p<.001$ ); young adults were better able to recollect prior attributes than were older adults, and prior locations were recollected more accurately than prior colors. The interaction between these factors was also reliable $(F=7.25, p<$ $.01)$. Interpretation of this interaction is made difficult by the low recollection of color in both groups. Nevertheless, it seems safe to conclude that recollection of a word's prior color was difficult for both groups (albeit greater than zero for the young) and that young adults were able to recollect prior locations much more accurately than were older adults.

Separate univariate analyses were performed on the two familiarity measures [corrected $F\left(M S_{\mathrm{e}}=0.0224\right)$ and $d^{\prime}$ $\left.\left(M S_{\mathrm{e}}=0.301\right)\right]$, both of which revealed the same pattern of results: The main effect of age was reliable $[F(1,140)=$ 25.02 for corrected $F$ and 34.84 for $d^{\prime}, p$ s $\left.<.001\right]$, as was the main effect of retrieval condition $[F(1,140)=10.47$ for corrected $F$ and 6.71 for $\left.d^{\prime}, p \mathrm{~s}<.05\right]$. The interaction between these two factors, however, fell just shy of the .05 alpha level $[F(1,140)=2.94$ for corrected $F$ and 3.03 for $d^{\prime}, p \mathrm{~s}=.088$ and .084 , respectively]. The marginal interactions likely reflect the slight (albeit nonsignificant) elevation in $F$ estimates for the older adults in the color condition, as compared with those in the location condition. Indeed, as will be discussed more fully below, Parks (2004) has recently shown that older adults are, in fact, capable of showing noncriterial recollection effects, at least under conditions in which recollection is relatively high. Thus, on the basis of our initial analysis of the older adults' data, which failed to show effects of noncriterial recollection, coupled with the clear effects in the young, we take the present analyses as indicating a reliable reduction in the effects of noncriterial recollection as a function of age.
Less equivocal is the effect of age on overall estimates of $F$; regardless of the how $F$ was measured, older adults showed reliably lower levels of estimated familiarity. ${ }^{3}$

In summary, recollection was greater in the young adults than in the older adults, and recollection was greater for location than for color for both age groups. Only the young, however, showed clear, reliable effects of noncriterial recollection on estimated familiarity. The young adults also showed reliably higher levels of estimated familiarity, an effect that appears to be at least partially due to the higher false alarm rates shown by the older adults.

\section{DISCUSSION}

The goal of the present experiment was to examine a curious but potentially important phenomenon in the PD literature - the finding that estimates of familiarity may reflect not only undifferentiated feelings of oldness, but also recollection of details that, nevertheless, do not support discriminative responding on inclusion and exclusion tests (Gruppuso et al., 1997; Mulligan \& Hirshman, 1997; see also Perfect, Mayes, Downes, \& Van Eijk, 1996). On the face of it, this result would seem to pose problems for the PD procedure. It also raises the important theoretical question of whether recollection of noncriterial details shows age-related declines or is, instead, age invariant.

In a study with young adults, Yonelinas and Jacoby (1996a) manipulated response speed at test in order to examine the relation between criterial and noncriterial recollection. They found that although noncriterial recollection increased familiarity estimates (being higher in a difficult retrieval condition than in an easier retrieval condition), those estimates were nevertheless invariant over a response speed manipulation that had a significant effect on recollection. That is, the effects of noncriterial recollection were functionally independent from those of criterial recollection. This led Yonelinas and Jacoby (1996a) to conclude that "perhaps noncriterial recollection is most appropriately treated as being familiarity" (p. 139, emphasis added).

The present study was designed to determine whether a similar finding would obtain in the context of aging. That is, prior research has shown that aging, like manipulations of response speed, has a detrimental impact on recollection but leaves estimated familiarity intact (e.g., Jennings \& Jacoby, 1993). Similarly, older adults generally show memory deficits on explicit tests of free and cued recall, when compared with the young, but little or no deficits on implicit tests (see Light et al., 2000). On the basis of these results, along with the assumption that noncriterial recollection is often fast and unbidden (i.e., automatic), one might have expected the effects of noncriterial recollection on estimated $F$ to be similar for younger and older adults. Yet despite clearly replicating the influence of noncriterial recollection on $F$ in young adults, we found little evidence of such influence in the older adults. We also found estimated $F$ to be smaller overall for the older adults, in contrast to much past research.

In the remainder of this discussion, we will focus on three questions. First, why did older adults in the pres- 
ent study fail to show effects of noncriterial recollection? Second, what explains the effect of age on overall estimated familiarity? Finally, is the influence of noncriterial recollection on familiarity an artifact of the PD procedure, or does it constitute a real phenomenon that should be addressed by dual-process theories of memory? We will conclude with suggestions for future research.

\section{The Relation Between Criterial and Noncriterial Recollection in the Context of Aging}

Yonelinas and Jacoby (1996a) found that although noncriterial recollection elevated estimated familiarity, that elevation was constant over a response speed manipulation that reliably decreased recollection. The present study shows that this pattern of results does not invariably extend to aging.

Why did the older adults in the present study not show effects of noncriterial recollection similar to those shown by the younger adults? We believe that the most likely reason is that the older adults did not have sufficient recollection of location to reliably contribute to (or contaminate) their estimate of $F$ in the color retrieval condition. To better understand this possibility, consider again the work of Yonelinas and Jacoby (1996a). In their study, recollection was reduced in the speeded-responding group, in comparison with the nonspeeded group. However, if a random assignment of participants is assumed, it is likely that the participants in the speeded group could have recollected more about test locations if they had been given the opportunity (i.e., if they had been able to respond at their own pace). Stated differently, although conscious access to location information in the size retrieval condition may have been undermined by speeded retrieval, such information was still potentially retrievable under less taxing conditions. Stated in the terminology of Tulving and Pearlstone (1966), although location information was not accessible in the speeded group, such information was nevertheless available.

The situation is different when the comparison involves older adults. That is, unlike Yonelinas and Jacoby's (1996a) speeded young participants, older adults in the present study were allowed to respond at their own pace and, thus, were likely showing near maximal recollection (cf. Jacoby, 1999). In the present study, recollection of location for young adults in the location condition was relatively high $(R=.32)$. If one assumes that the young adults in the color condition could have recollected location at a similar level (had they been asked), the potential for noncriterial recollection was also relatively high. In contrast, the older adults in the location condition recollected prior locations at a much lower level $(R=.15)$. If one assumes that this provides a general index of the ability of older adults to recollect locations in the color condition, the potential for noncriterial recollection to influence performance would be less than half that shown by the young. The present results thus seem most consistent with the idea that the impact of noncriterial recollection on estimated $F$ depends on potential recollection - that is, the amount of noncriterial information that could be retrieved if such information was directly queried.
Support for this hypothesis has come from a recent study by Parks (2004), who extended the phenomenon of noncriterial recollection to the remember/know procedure. In contrast to the present study, Parks found that recollection of noncriterial attributes can elevate both know judgments and estimated familiarity in older adults. Critically, however, older adults' recollection of those attributes when directly queried (approximately .30) was nearly twice the level of recollection observed in the present study (.15). This result is consistent with our claim that the effects of noncriterial recollection on estimated familiarity are tied to an individual's overall ability to recollect studied details. As additional support for this notion, Parks found that when young adults' ability to recollect a studied attribute was reduced by dividing their attention at encoding, the contribution of that attribute to estimated familiarity (i.e., the noncriterial recollection effect) was also reduced, relative to full-attention encoding conditions. Both of these findings, then, support the present claim that the effects of noncriterial recollection on estimated familiarity depend on the degree to which earlier encoded attributes could be recollected under criterial-testing conditions (i.e., when memory is directly queried). ${ }^{4}$

Although our explanation of why older adults failed to show an effect of noncriterial recollection may seem somewhat obvious (in the sense of you can't use what you don't have), it does have at least one rather nonobvious implication for measuring familiarity and understanding how it changes with age. In particular, if recollection of noncriterial information is tied to the ability to recollect such information when memory is directly queried (i.e., when such information is criterial) and if age is associated with a general decrease in recollection, the impact of noncriterial recollection on estimated $F$ should decline with age.

\section{The Effect of Age on Familiarity}

A major question raised by the present study is why we found an effect of age on overall $F$ when prior research (Caldwell \& Masson, 2001; Jacoby, 1996, 1999; Jennings \& Jacoby, 1993, 1997; Rybash \& Hoyer, 1996; Titov \& Knight, 1997) has found $F$ to be age invariant. One possibility, consistent with the discussion above, is that the higher levels of $F$ found for the young simply reflect a greater degree of noncriterial recollection in both retrieval conditions. By defining recollection in terms of two relatively low-level dimensions, we made all other recollected information (e.g., thoughts, images, etc.) noncriterial and, thus, able to contribute to $F$. In contrast, in prior studies in which the effects of age on familiarity have been investigated relatively distinctive (discriminable) lists have been used, thereby reducing the potential contribution of noncriterial recollection. Distinctive lists will tend to reduce the contribution of noncriterial recollection to performance by increasing the probability that a retrieved detail will specify the (criterial) study context. By this account, our finding of an age effect on $F$ stems from our use of highly specific definitions of recollection, definitions that allowed noncriterial recollection to have a relatively large impact on estimated $F$. 
A related possibility for why we found an age effect on $F$ is that there may actually be a true age-related deficit in undifferentiated (or pure) familiarity that is revealed only when memory is queried for specific details. That is, by focusing the participants' attention on color and location, we may have altered the factors that typically determine undifferentiated $F$. Research generally consistent with this possibility has come from studies of spontaneous recognition (Ste-Marie \& Jacoby, 1994; see also Jacoby, Ste-Marie, \& Toth, 1993) and of source monitoring (e.g., Hashtroudi, Johnson, \& Chrosniak, 1990; Hashtroudi, Johnson, Vnek, \& Ferguson, 1994), and from those in which the relation between perspective taking and memory has been examined (e.g., Anderson \& Pichert, 1978; Tversky \& Marsh, 2000). Also consistent with this perspective is recent work showing that the determinants of recognition performance can change, depending on how memory for prior events is queried (Humphreys, Dennis, Maguire, Reynolds, Bolland, \& Hughes, 2003). Finally, research by Light, Prull, and their colleagues (see Light et al., 2000; Prull, Crandell, Martin, Backus, \& Light, 2003), as well as by Parks (2004), suggests that contrary to many previous claims, age may be associated with small but measurable declines in familiarity (see also Davidson \& Glisky, 2002). Parks's research is especially noteworthy, since remember/know and confidence-rating procedures were used to further explore noncriterial recollection in the context of aging, thereby extending and generalizing the phenomenon beyond the PD procedure. Replicating the present study, Parks found age-related decreases in the impact of noncriterial recollection on estimated familiarity, along with age-related declines in overall familiarity. Thus, although our finding of age-related declines in familiarity conflicts with some prior work, there are both theoretical reasons and empirical precedence for expecting such declines, at least under some circumstances.

\section{Noncriterial Recollection as Familiarity: Real Phenomenon or Measurement Artifact?}

A final question that begs to be addressed is whether the effect of noncriterial recollection on $F$ should be considered a real memory phenomenon, in the sense that noncriterial recollection is appropriately measured and/ or subjectively experienced as familiarity, or whether it is simply an artifact of the PD procedure, in which case estimates of $F$ that include noncriterial recollection are overestimates of true undifferentiated familiarity.

The former position has been most strongly advocated by Gruppuso et al. (1997), who stated that "it is precisely the retrieval of episodic memory information-information too incomplete to support unique identification - that gives rise to the nagging feeling of familiarity" (p. 273). For this position, then, not only are consciously retrieved noncriterial details appropriately measured as $F$, but such details actually increase one's subjective sense of familiarity. A similar, albeit less radical, position was taken by Yonelinas and Jacoby (1996a). That is, although not taking a stand on the experiential correlates of noncriterial recollection (i.e., whether it is experienced as familiarity), they argued that noncriterial recollection is, nevertheless, independent of criterial recollection, thus making noncriterial recollection "functionally equivalent" to $F$. Although they are consistent with the data on which they were based, it is not entirely clear how these two positions could reconcile (1) prior findings of age-related invariance in $F$ with (2) age-related reductions in the influence of noncriterial recollection (such as those shown in the present study and in Parks, 2004). That is, if noncriterial recollection is to be interpreted as functionally equivalent to familiarity, there is no reason to expect an age-related reduction in the influence of noncriterial recollection or a main effect of age on $F$.

The second position (estimated $F$ as artifact) has been taken by Mulligan and Hirshman (1997; see also Dodson \& Johnson, 1996), who stated that "the PD parameter of familiarity is inappropriately affected by aspects of nondiagnostic [noncriterial] recollection" (p. 280, emphasis added). On this view, noncriterial (nondiagnostic) recollection is not a valid subjective experience that is appropriately captured in familiarity estimates, nor should it be interpreted as functionally equivalent to familiarity. Rather, such recollection always acts as a contaminate of the familiarity estimates, resulting in underestimation of true recollection, overestimation of true familiarity, and the production of spurious dissociations as a result of mismeasurement. Also worth noting is Mulligan and Hirshman's argument that all precautions against noncriterial recollection may be in vain, given the difficulty of determining a priori whether participants have retrieved details that are noncriterial for the test question of interest. As such, and given their further reservations about familiarity as conventionally defined by dual-process models, they argued that PD estimates may always be suspect.

We believe that a third position may be more defensible than either of the two outlined above, such that $F$ as measured in the PD procedure reflects both undifferentiated feelings of familiarity and noncriterial recollection and these two influences are dissociable and measurable. In support of this position, we note that introspection suggests that familiarity is often an undifferentiated experience, providing a general feeling of pastness but no clear information about episodic details or the source of such feelings. More important, there is a great deal of research (e.g., Jacoby \& Whitehouse, 1989; LeCompte, 1995; Lindsay \& Kelley, 1996; Rajaram, 1993; Whittlesea, 1993; Whittlesea \& Williams, 2000) showing that manipulations of processing fluency at test can elevate judgments of oldness, irrespective of the study status of the test items (i.e., whether the test item is actually old or new). It is generally believed that these manipulations have their effect by increasing undifferentiated feelings of familiarity (see, e.g., Whittlesea, 1993). Of course, this is not to say that noncriterial recollection does not sometimes produce subjective feelings that are similar, if not indistinguishable, from episodic familiarity (cf. Gruppuso et al., 1997; Perfect et al., 1996). Nevertheless, research in which familiarity has been manipulated through fluency, along with the present results showing that the effects of 
noncriterial recollection can be dissociated as a function of age, suggests that noncriterial recollection is conceptually distinct from undifferentiated familiarity.

\section{Conclusions and Suggestions for Future Research}

With testing procedures that inquired about the specific details of a prior event, the present study showed agerelated decreases in both estimated familiarity and the impact of noncriterial recollection on estimated familiarity. The results stand in contrast to previous findings of age invariance in familiarity and suggest the need for additional research in which memory will be examined for specific event details. PD research in which the effect of age on familiarity has been examined has tended to use relatively simple stimuli, such as isolated words or line drawings. Future research should examine familiarity for richer, more complex stimuli that allow for greater degrees of noncriterial recollection. Although age invariance in familiarity is, at present, a widely accepted finding in the dual-process literature, it seems possible that this conclusion is dependent on the use of relatively simple stimuli, coupled with test conditions that allow recollection to be supported by a wide range of retrieved attributes. Examining memory for more complex events may help identify important boundary conditions for the claim that familiarity is an age-invariant form of memory.

It also seems worthwhile to examine memory for specific event details by using measures of subjective experience, such as the remember/know procedure (Gardiner \& Richardson-Klavehn, 2000) or the Memory Characteristics Questionnaire (Johnson, Foley, Suengas, \& Raye, 1988). Use of such procedures could help address the question, raised by Gruppuso et al. (1997), of whether recollection of noncriterial attributes can actually elevate subjective experiences of undifferentiated familiarity. Answering that question would deepen our understanding of the informational basis of recollection and familiarity, as well as the relation between the two.

\section{REFERENCES}

Aggleton, J. P., \& Shaw, C. (1996). Amnesia and recognition memory: A re-analysis of psychometric data. Neuropsychologia, 34, 51-62.

Anderson, R. C., \& Pichert, J. W. (1978). Recall of previously unrecallable information following a shift in perspective. Journal of Verbal Learning \& Verbal Behavior, 17, 1-12.

Atkinson, R. C., \& Juola, J. F. (1974). Search and decision processes in recognition memory. In D. H. Krantz, R. C. Atkinson, R. D. Luce, \& P. Suppes (Eds.), Contemporary developments in mathematical psychology: Vol. 1. Learning, memory, and thinking (pp. 243-293). San Francisco: Freeman.

Balota, D. A., Dolan, P. O., \& Duchek, J. M. (2000). Memory changes in healthy older adults. In E. Tulving \& F. I. M. Craik (Eds.), The Oxford handbook of memory (pp. 395-409). Oxford: Oxford University Press.

Benjamin, A. S., \& Craik, F. I. M. (2001). Parallel effects of aging and time pressure on memory for source: Evidence from the spacing effect. Memory \& Cognition, 29, 691-697.

Braver, T. S., \& BARCH, D. M. (2002). A theory of cognitive control, aging cognition, and neuromodulation. Neuroscience \& Biobehavioral Reviews, 26, 809-817.

Caldwell, J. I., \& Masson, M. E. J. (2001). Conscious and uncon- scious influences of memory for object location. Memory \& Cognition, 29, 285-295.

Craik, F. I. M., \& Grady, C. L. (2002). Aging, memory, and frontal lobe functioning. In D. T. Stuss \& R. T. Knight (Eds.), Principles of frontal lobe function (pp. 528-540). Oxford: Oxford University Press.

Craik, F. I. M., \& Jennings, J. M. (1992). Human memory. In F. I. M. Craik \& T. A. Salthouse (Eds.), The handbook of aging and cognition (pp. 51-110). Hillsdale, NJ: Erlbaum.

Curran, T. (2000). Brain potentials of recollection and familiarity. Memory \& Cognition, 28, 923-938.

Curran, T., \& Hintzman, D. L. (1995). Violations of the independence assumption in process dissociation. Journal of Experimental Psychology: Learning, Memory, \& Cognition, 21, 531-547.

Curran, T., \& Hintzman, D. L. (1997). Consequences and causes of correlation in process dissociation. Journal of Experimental Psychology: Learning, Memory, \& Cognition, 23, 496-504.

DAVIDSON, P. S. R., \& GLISKY, E. L. (2002). Neuropsychological correlates of recollection and familiarity in normal aging. Cognitive, Affective, \& Behavioral Neuroscience, 2, 174-186.

Dodson, C. S., Holland, P. W., \& Shimamura, A. P. (1998). On the recollection of specific- and partial-source information. Journal of Experimental Psychology: Learning, Memory, \& Cognition, 24, 11211136.

Dodson, C. S., \& Johnson, M. K. (1996). Some problems with the process-dissociation approach to memory. Journal of Experimental Psychology: General, 125, 181-194.

Gardiner, J. M., \& Richardson-Klavehn, A. (2000). Remembering and knowing. In E. Tulving \& F. I. M. Craik (Eds.), The Oxford handbook of memory (pp. 229-244). Oxford: Oxford University Press.

Graf, P., \& Komatsu, S. (1994). Process dissociation procedure: Handle with caution! European Journal of Cognitive Psychology, 6, 113129.

Gruppuso, V., Lindsay, D. S., \& Kelley, C. M. (1995, November). Redefining and estimating recollection and familiarity with the process dissociation procedure. Paper presented at the 36th Annual Meeting of the Psychonomic Society, Los Angeles.

Gruppuso, V., Lindsay, D. S., \& Kelley, C. M. (1997). The processdissociation procedure and similarity: Defining and estimating recollection and familiarity in recognition memory. Journal of Experimental Psychology: Learning, Memory, \& Cognition, 23, 259-278.

Hashtroudi, S., Johnson, M. K., \& Chrosniak, L. D. (1990). Aging and qualitative characteristics of memories for perceived and imagined complex events. Psychology \& Aging, 5, 119-126.

Hashtroudi, S., Johnson, M. K., VneK, N., \& Ferguson, S. A. (1994). Aging and the effects of affective and factual focus on source monitoring and recall. Psychology \& Aging, 9, 160-170.

Henson, R. N., Rugg, M. D., Shallice, T., Josephs, O., \& Dolan, R. J. (1999). Recollection and familiarity in recognition memory: An event-related functional magnetic resonance imaging study. Journal of Neuroscience, 19, 3962-3972.

Hintzman, D. L., Caulton, D. A., \& Levitin, D. J. (1998). Retrieval dynamics in recognition and list discrimination: Further evidence of separate processes of familiarity and recall. Memory \& Cognition, 26, 449-462.

Humphreys, M. S., Dennis, S., Chalmers, K. A., \& Finnigan, S. (2000). Dual processes in recognition: Does a focus on measurement operations provide a sufficient foundation? Psychonomic Bulletin \& Review, 7, 593-603.

Humphreys, M. S., Dennis, S., Maguire, A. M., Reynolds, K., BolLAND, S. W., \& HuGHES, J. D. (2003). What you get out of memory depends on the question you ask. Journal of Experimental Psychology: Learning, Memory, \& Cognition, 29, 797-812.

JACOBY, L. L. (1991). A process dissociation framework: Separating automatic from intentional uses of memory. Journal of Memory \& Language, 30, 513-541.

JACOBY, L. L. (1996). Dissociating automatic and consciously controlled effects of study/test compatibility. Journal of Memory \& Language, 35, 32-52.

JACOBY, L. L. (1998). Invariance in automatic influences of memory: Toward a user's guide for the processes dissociation procedure. Journal of Experimental Psychology: Learning, Memory, \& Cognition, 24, 3-26. 
JACOBY, L. L. (1999). Ironic effects of repetition: Measuring age-related differences in memory. Journal of Experimental Psychology: Learning, Memory, \& Cognition, 25, 3-22.

JACOBY, L. L., BEGG, I. M., \& ToTH, J. P. (1997). In defense of functional independence: Violations of assumptions underlying the processdissociation procedure? Journal of Experimental Psychology: Learning, Memory, \& Cognition, 23, 484-495.

Jacoby, L. L., Jennings, J. M., \& HaY, J. F. (1996). Dissociating automatic and consciously controlled processes: Implications for diagnosis and rehabilitation of memory deficits. In D. Herrmann, C. McEvoy, C. Hertzog, P. Hertel, \& M. K. Johnson (Eds.), Basic and applied memory research (Vol. 1, pp. 161-193). Mahwah, NJ: Erlbaum.

JACOBY, L. L., \& Kelley, C. M. (1992). Unconscious influences of memory: Dissociations and automaticity. In A. D. Milner \& M. D. Rugg (Eds.), The neuropsychology of consciousness (pp. 201-233). San Diego: Academic Press.

Jacoby, L. L., Ste-Marie, D. M., \& Toth, J. P. (1993). Redefining automaticity: Unconscious influences, awareness, and control. In A. D. Baddeley \& L. Weiskrantz (Eds.), Attention: Selection, awareness, and control. A tribute to Donald Broadbent (pp. 261-282). New York: Oxford University Press.

JACOBY, L. L., \& Whitehouse, K. (1989). An illusion of memory: False recognition influenced by unconscious perception. Journal of Experimental Psychology: General, 118, 126-135.

JenNings, J. M., \& JACOBY, L. L. (1993). Automatic versus intentional uses of memory: Aging, attention, and control. Psychology \& Aging, 8, 283-293.

JenNings, J. M., \& JACOBY, L. L. (1997). An opposition procedure for detecting age-related deficits in recollection: Telling effects of repetition. Psychology \& Aging, 12, 352-361.

Johnson, M. K., Foley, M. A., Suengas, A. G., \& Raye, C. L. (1988). Phenomenal characteristics of memories for perceived and imagined autobiographical events. Journal of Experimental Psychology: General, 117, 371-376.

KUČERA, H., \& FRANCIS, W. N. (1967). Computational analysis of presentday American English. Providence, RI: Brown University Press.

La Voie, D., \& Light, L. L. (1994). Adult age differences in repetition priming: A meta-analysis. Psychology \& Aging, 9, 539-553.

LECompte, D. C. (1995). Recollective experience in the revelation effect: Separating the contributions of recollection and familiarity. Memory \& Cognition, 23, 324-334.

Light, L. L., Prull, M. W., La Voie, D. J., \& Healy, M. R. (2000). Dual-process theories of memory in old age. In T. J. Perfect \& E. A. Maylor (Eds.), Models of cognitive aging: Debates in psychology (pp. 238-300). Oxford: Oxford University Press.

LindSAY, D. S., \& Kelley, C. M. (1996). Creating illusions of familiarity in a cued recall remember/know paradigm. Journal of Memory \& Language, 35, 197-211.

MANDLER, G. (1980). Recognizing: The judgment of previous occurrence. Psychological Review, 87, 252-271.

Mulligan, N. W., \& Hirshman, E. (1997). Measuring the bases of recognition memory: An investigation of the process-dissociation framework. Journal of Experimental Psychology: Learning, Memory, \& Cognition, 23, 280-304.

Park, D. C., Polk, T. A., Mikels, J. A., Taylor, S. F., \& Marshuetz, C. (2001). Cerebral aging: Integration of brain and behavioral models of cognitive function. Dialogues in Clinical Neuroscience, 3, 151-165.

PARKS, C. M. (2004). Noncriterial recollection in young and older adults: The effects of defining recollection specifically in the remember-know and dual process signal detection paradigms. Unpublished doctoral dissertation, Georgia Institute of Technology.

Perfect, T. J., MaYes, A. R., Downes, J. J., \& VAN EiJK, R. (1996). Does context discriminate recollection from familiarity in recognition memory? Quarterly Journal of Experimental Psychology, 49A, 797-813.

Prull, M. W., Crandell, L. L., Martin, A. M., III, Backus, H. F., \& Light, L. L. (2003, November). Adult age differences in familiarity depend on which process estimation method is used. Poster presented at the 44th Annual Meeting of the Psychonomic Society, Vancouver.

RAJARAM, S. (1993). Remembering and knowing: Two means of access to the personal past. Memory \& Cognition, 21, 89-102.
Rybash, J. M., \& HoyeR, W. J. (1996). Process dissociation procedure reveals age differences in unconscious influences on memory for possible and impossible objects. Aging, Neuropsychology, \& Cognition, 3, 251-263.

Schmitter-Edgecombe, M. (1999). Effects of divided attention and time course on automatic and controlled components of memory in older adults. Psychology \& Aging, 14, 331-345.

Searcy, J. H., Bartlett, J. C., \& Memon, A. (1999). Age differences in accuracy and choosing in eyewitness identification and face recognition. Memory \& Cognition, 27, 538-552.

Ste-Marie, D. M., \& JACOBY, L. L. (1994). Spontaneous versus directed recognition: The relativity of automaticity. Journal of Experimental Psychology: Learning, Memory, \& Cognition, 19, 777-788.

Stuss, D. T., Craik, F. I. M., Sayer, L., Franchi, D., \& Alexander, M. P. (1996). Comparison of older people and patients with frontal lesions: Evidence from word list learning. Psychology \& Aging, 11, 387-395.

Titov, N., \& KNight, R. G. (1997). Adult age differences in controlled and automatic memory processing. Psychology \& Aging, 12, 565573.

ToтH, J. P. (1996). Conceptual automaticity in recognition memory: Levels-of-processing effects on familiarity. Canadian Journal of Experimental Psychology, 50, 123-138.

Toth, J. P., Reingold, E. M., \& JACOBY, L. L. (1995). A response to Graf and Komatsu's critique of the process dissociation procedure: When is caution necessary? European Journal of Cognitive Psychology, 7, 113-130.

Tulving, E., \& Pearlstone, Z. (1966). Availability versus accessibility of information in memory for words. Journal of Verbal Learning \& Verbal Behavior, 5, 381-391.

Tversky, B., \& Marsh, E. J. (2000). Biased retellings of events yield biased memories. Cognitive Psychology, 40, 1-38.

Verfaellie, M., \& Treadwell, J. R. (1993). Status of recognition memory in amnesia. Neuropsychology, 29, 641-657.

Whittlesea, B. W. A. (1993). Illusions of familiarity. Journal of Experimental Psychology: Learning, Memory, \& Cognition, 19, 12351253.

Whittlesea, B. W. A., \& Williams, L. D. (2000). The source of feelings of familiarity: The discrepancy-attribution hypothesis. Journal of Experimental Psychology: Learning, Memory, \& Cognition, 26, 547-565.

Yonelinas, A. P. (1994). Receiver-operating characteristics in recognition memory: Evidence for a dual-process model. Journal of Experimental Psychology: Learning, Memory, \& Cognition, 20, 13411354.

Yonelinas, A. P. (1997). Recognition memory ROCs for item and associative information: The contribution of recollection and familiarity. Memory \& Cognition, 25, 747-763.

Yonelinas, A. P. (2001). Consciousness, control, and confidence: The 3 Cs of recognition memory. Journal of Experimental Psychology: General, 130, 361-379.

Yonelinas, A. P. (2002). The nature of recollection and familiarity: A review of 30 years of research. Journal of Memory \& Language, 46, 441-517.

Yonelinas, A. P., \& JACOBY, L. L. (1994). Dissociations of processes in recognition memory: Effects of interference and of response speed. Canadian Journal of Experimental Psychology, 48, 516-534.

Yonelinas, A. P., \& JACOBY, L. L. (1996a). Noncriterial recollection: Familiarity as automatic, irrelevant recollection. Consciousness \& Cognition, 5, 131-141.

YonelinAS, A. P., \& JACOBY, L. L. (1996b). Response bias and the processdissociation procedure. Journal of Experimental Psychology: General, 125, 422-434.

Yonelinas, A. P., Hopfinger, J. B., Buonocore, M. H., Kroll, N. E. A., \& BAYNES, K. (2001). Hippocampal, parahippocampal and occipital-temporal contributions to associative and item recognition memory: An fMRI study. NeuroReport, 12, 359-363.

Yonelinas, A. P., Kroll, N. E. A., Dobbins, I., Lazzara, M., \& KNIGHT, R. T. (1998). Recollection and familiarity deficits in amnesia: Convergence of remember-know, process dissociation, and receiver operating characteristic data. Neuropsychology, 12, 323-339. 


\section{NOTES}

1. Due to experimenter error, the Shipley test was administered to only 46 of the 72 young adults.

2 . For each participant, $d^{\prime}$ was calculated from standard $d^{\prime}$ tables, using the estimated $F$ value as the hit rate and the proportion of "yes" responses to new items as the false alarm rate. For 4 participants who had zero false alarms ( 3 young, 1 old), we used a false alarm value of .01 .

3. Ceiling and floor effects are known to distort estimates of familiarity (see Curran \& Hintzman, 1995; Jacoby, 1998), and Yonelinas (2002) has recently suggested that high levels of recollection $(>.60)$ may also distort these estimates. It is, therefore, worth noting that inclusion and exclusion performance in the present study was in the middle of the scale (ranging from .36 to .69) and that all recollection estimates were below .40. It would thus appear that the estimates obtained in the present study are valid vis-à-vis previous uses of the PD procedure.
4. An important issue is the quantitative relation between the elevation in estimated $F$ due to recollection of noncriterial attributes and the level of recollection for those same attributes when they are criterial. One appealing possibility is that the effect of noncriterial recollection on $F$ is proportional to criterial recollection. Indeed, Yonelinas and Jacoby's (1996a) data seem to exhibit such a proportional relation, although they found no statistical support for this relation. Similarly in the present study, when baselines are taken into account (by using corrected $F$ values), the relation between young/old differences in criterial recollection and the size of the noncriterial recollection effect on $F$ does not appear proportional. Overall, then, the specific quantitative relation between criterial recollection and the effect of noncriterial recollection on estimated $F$ will have to await further research.

(Manuscript received May 24, 2004; revision accepted for publication April 28, 2005.) 